\title{
Panel Data Analysis on the Influence of Environmental Regulations on the Inflow of Foreign Direct Investment in China
}

\author{
Hao Hu${ }^{1 *}$, Lei Dong ${ }^{2}$, Hao Zhang ${ }^{1}$, Haiyan Tang ${ }^{3}$, Desheng Yin ${ }^{4}$ \\ ${ }^{1}$ School of Economics, Shanghai University, Shanghai 200444, China \\ ${ }^{2}$ Hefei Branch, China Merchants Bank, Hefei 230000, China \\ ${ }^{3}$ Headmaster's Office, Shanghai Business School, Shanghai 200235, China \\ ${ }^{4}$ Faculty of Economics, East China Normal University, Shanghai 200063, China
}

Corresponding Author Email: huhao@staff.shu.edu.cn

https://doi.org/10.18280/ijsdp.150708

Received: 19 May 2020

Accepted: 27 August 2020

\section{Keywords:}

environmental regulations (ERS), foreign direct investment (FDI), pollution haven hypothesis, porter hypothesis

\begin{abstract}
From the micro level, this paper thoroughly investigates the influence of environmental regulations (ERS) on the inflow of foreign direct investment (FDI) in China. Firstly, the entropy method was adopted to comprehensively measure the ERS intensities of 283 Chinese cities at prefecture level and above in 2003-2016. Then, the Cournot model was utilized to analyze how ERS affects FDI. After that, fixed-effects model was employed to empirically examine the impacts of ERS intensities in eastern, central, and western regions on FDI inflow. The results show that: The regression results on nationwide, central, and western samples indicate that the influence of ERS variable was significantly negative. This means ERS is indeed an important consideration of foreign investors in location selection. Besides, stricter ERS hinders the inflow of FDI, which agrees with the pollution haven hypothesis. On eastern samples, stricter ERS promotes FDI inflow, that is, the situation in eastern region meets Porter hypothesis. Finally, several suggestions were presented for policymakers based on the empirical results.
\end{abstract}

\section{INTRODUCTION}

In the context of economic globalization, foreign direct investment (FDI) is one of the main drivers of Chinese economy. According to the World Investment Report 2020, the global FDI inflow in 2019 amounted to USD 1.53988 trillion, up by $3.0 \%$ over the previous year; the global FDI outflow in 2019 stood at USD 1.31377 trillion, an increase of 33.2\% over the previous year. Since the reform and opening-up, the inflow of foreign capital has made up China's shortfall in capital, and promoted the introduction of advanced foreign technology and management talents, thereby stimulating economic growth in the country. In the recent years, China has been attracting a growing amount of FDI. In 2019, 41,000 foreign-invested enterprises were founded, and USD 1.7 billion foreign capital was actually utilized, a year-on-year increase of $5.8 \%$.

Despite the continuous growth, FDI in China is distributed very unevenly. There is a huge gap in actually utilized FDI. Most of China's FDI concentrates in the eastern region, especially in the Yangtze River Delta and the Pearl River Delta. Although some foreign capital has migrated to the central and western regions under the strategies of Western Development and Rise of Central China, the eastern region is utilizing a far greater amount of foreign capital than the central and western regions. Studies have suggested that $90 \%$ of the difference in economic development between the eastern, central, and western regions arises from the regional difference in foreign capital. Thus, FDI contributes greatly to the imbalanced development between the regions.

Against this backdrop, it is very meaningful to explore the following questions: What caused the difference of FDI in location selection? How should the relatively underdeveloped central and western regions attract foreign capital, and narrow the gap with the eastern region in the actual utilization of FDI?

While propelling economic growth, the continuous influx of foreign capital brings prominent environmental problems to the host country. Proposed by Walter and Ugelow [1], the pollution haven hypothesis points out that: Facing strict environmental regulations (ERS) in developed countries, multinational enterprises often relocate polluting industries to developing countries, where ERS is relatively relaxed due to the low level of economic development; as a result, polluting industries flow from developed countries to developing countries, making the latter a gathering place of pollution.

In China, the FDI inflow and economic growth have exerted a huge pressure on the environment. Some scholars held that stricter ERS can significantly suppress pollution in various regions, and foreign investment under ERS can reduce the amount and intensity of carbon emissions [2, 3]. The Porter hypothesis, named after American scholar Michael Porter, suggests that strict ERS forces enterprises to pursue technological innovation, and offset the cost of ERS compliance with the compensation effect of innovation; therefore, strict ERS can cut down pollution, boost corporate profit, and attract FDI inflow.

Faced with increasingly serious environmental problems, China is rolling out more and more stringent ERS policies. To protect and improve the environment, China started to implement an updated Environmental Protection Law (EPL) as of January 1, 2015. Dubbed the most stringent law in 
Chinese history, this version of EPL strictly regulates the pollution discharge of enterprises, and impose severe penalties on those failing to comply with pollution discharge standards. Since 1995, the inflow of foreign capital to China has been regulated and guided to meet the needs of economic development.

In spite of the above efforts, environmental pollution in China is worsening with the increasing inflow of foreign capital. Many started to wonder whether the deterioration of the environment is associated with the inflow of foreign capital, and whether the introduction of foreign capital has boosted China's economic growth. Hence, the relationships among FDI, environmental pollution, and ERS have become a research hotspot.

Currently, scholars disagree on how ERS affects FDI inflow. Some scholars believe that ERS inhibits the inflow of FDI [47]. Some argued that stricter ERS can promote the FDI inflow [8-10]. Some highlighted the asymmetry between ERS and FDI [11].

It is worth mentioning that it is difficult to directly measure the ERS intensity. In fact, there is not yet a unified measuring method. This might be the main reason for the above disagreement. Besides, the indices selected by different scholars to measure ERS intensity are highly inconsistency. Most scholars rely on a single index to evaluate ERS intensity. Thus, the evaluation is inevitably one-sided, failing to fully reflect the ERS level. What is worse, the various indices chosen by different scholars are not comparable.

To solve the above problems, this paper constructs a comprehensive measuring index for ERS intensity, investigates the influence of ERS on the FDI inflows in eastern, central, and western regions from cities at prefecture level and above, and explores two mechanisms of ERS on FDI inflow based on the Cournot model.

The remainder of this paper is organized as follows: Section 2 summarizes the relevant literature; Section 3 analyzes the influence of ERS on FDI inflow with the Cournot model; Section 4 explains the empirical model, variable selection, measurement, and data sources; Section 5 analyzes the results of empirical analysis; Section 6 puts forward the conclusions.

\section{LITERATURE REVIEW}

Owing to the difference in research object and method, scholars at home and abroad draw varied conclusions on the relationship between FDI and ERS. In general, there are three different views about the relationship.

The first view is that ERS inhibits the inflow of FDI, which agrees with the pollution haven hypothesis. This hypothesis believes that, due to the relatively strict ERS in developed countries, multinational enterprises often relocate pollutionintensive industries to developing countries with relatively relaxed ERS, aiming to reduce corporate cost and maximize profit. This is because relaxed ERS favors the inflow of foreign capital, while a strict ERS inhibits that inflow. Moreover, the host countries, driven by economic globalization and the free flow of capital, compete to attract foreign capital by lowering their ERS standards. The race to the bottom further intensifies environmental problems.

Birdsall and Wheeler [4] held that, in the 1980s, developed countries implemented very strict ERS, forcing many multinational enterprises to transfer polluting industries to developing countries with relaxed ERS. Rema [12], Dam and
Scholtens [7] also pointed out some polluting enterprises in developed countries have transferred polluting industries to countries with lower ERS levels, trying to reduce cost and expand profit. Chung [13] examined the FDI patterns in South Korea from 2000 to 2014 , and found that polluting industries tend to invest in countries with relatively relaxed ERS, judging by the amount of investment and the number of new foreign subsidiaries. Millimet and Roy [14] empirically analyzed the data of the fifty states in the United States (US), and discovered the negative impact of ERS on FDI. Lin and Sun [15] demonstrated that fewer FDI enterprises are established in provinces with strict ERS (i.e. high pollution tax rate). Naughton [16], Cai et al. [17], Xu et al. [18], Geonwoo [19], Li et al. [20], Mulatu [21], and Cheng et al. [22] also suggested that strict ERS will reduce FDI, and FDI tends to flow to cities with relaxed ERS. Yang et al. [23] stated that ERS has a negative impact on the introduction of FDI, but the impact is not significant across the country, and has obvious regional differences. Taking China as an example, Ge et al. [24] empirically evaluated the impact of ERS on FDI in developing countries, and concluded that (1) environmental policies suppress FDI inflow to provinces that strictly enforce environmental laws; (2) FDI in provinces that loosely enforce these laws is not sensitive to environmental policies.

The second view is that the increase in ERS has a certain promoting effect on the inflow of FDI, which is in line with the Porter hypothesis. The proposer of the hypothesis, Michael Porter, suggested that, rather than suppress FDI inflow, strict ERS by the government will force enterprises to pursue technological innovation, resulting in the innovation compensation effect. Specifically, the government's implementation of strict ERS will increase the environmental cost of enterprises, but it will also stimulate enterprises to continuously innovate technology. The technological innovation will bring more profit to the enterprises, which offsets and even surpasses the cost increment induced by ERS. Apart from the possible additional profit, the enterprises will gain the first-mover advantage, and enjoy a better corporate image, attracting a greater FDI inflow.

Using the Cournot model, Dijkstra et al. [8] manifested that, under the strict ERS policies in the host country, the foreign enterprises will face a much smaller cost hike than domestic enterprises, and therefor ERS can promote FDI inflow. Under a self-designed theoretical framework, Elliott and Zhou [9] proved that stricter ERS will lead to an increase in the strategy of capital inflow, and defined the phenomenon as FDI caused by ERS. Dean [25] clarified that strict ERS is more attractive to foreign capital inflow. Based on the panel data of 120 developing countries from 2000 to 2014, Kim and Rhee [10] empirically studied whether strict ERS would hinder FDI in developing countries, and falsified the pollution haven hypothesis: strict ERS is highly attractive to FDI; the ERS of the host country could elevate domestic productivity, and attract the investment from foreign multinational enterprises.

The third view is that ERS has no impact on FDI inflow and its location selection. Walter [1] carefully examined the foreign investment situation of the US, Japan, and Western Europe from 1970 to 1978 , concluding that the transfer of polluting industries to developing countries is not driven by ERS differences. Eskeland [26] separately analyzed how the environmental standards in countries with different development models (e.g. Mexico and Venezuela) on the introduction of foreign investment, and learned that ERS is not correlated with FDI. Zugravu and Kheder [27] analyzed the 
data on French enterprises by spatial econometric model, revealing that the location distribution of FDI is not affected by ERS level. Hwang et al. [28] designed a pollutant index based on the emissions of eight pollutants, and measured ERS intensity with the index; the results show that ERS does not have a significant effect on the inflow of foreign capital to South Korea.

Considering the varied levels of relevant laws/regulations and the imperfect supervision and enforcement, it is a difficult task to directly measure ERS intensity [29]. Currently, there is no unified method for measuring ERS intensity. Based on the environmental democracy index (EDI), Yale Center for Environmental Law \& Policy, in association with the Center for International Earth Science Information Network (CIESIN), Columbia University, released the environmental performance indices (EPIs) of all countries over the years. Chakraborty and Mukherjee [30] and Adeel-Farooq et al. [31] empirically measured ERS intensity with the EPIs.

In addition, most of the existing empirical studies use a single index to measure ERS intensity, such as pollution control expenditure [3], emission reduction cost [14], effective collection rate, pollution control index [15], wastewater reduction rate [18], total pollution emissions, energy consumption per unit of gross domestic product (GDP), etc. Based on different data and measuring methods, scholars at home and abroad drew very different conclusions. For example, List and Co [5] adopted the conditional logarithmic model to evaluate how ERS influences the site selection of new plants of multinational enterprises and the introduction of FDI in each state, and observed that strict ERS has an adverse effect on the inflow of FDI. On the contrary, List [32] further studied the inflow of foreign capital to various counties in the US, and found that strict ERS has little effect on the FDI inflow.

In summary, the scholars hold different views because the indices selected by them to measure ERS intensity are inconsistent, noncomparable, and single-sided, failing to comprehensively reflect the ERS level. In addition, the current empirical research often targets national or provincial-level data, without considering the economic gap between regions or intra-provincial differences.

Based on the research purpose and data availability, this paper measures the ERS intensities of 283 Chinese cities at prefecture level and above with five indices (i.e. the removal rate of industrial sulfur dioxide, the removal rate of industrial fume, the comprehensive utilization rate of industrial solid waste, the treatment rate of domestic sewage, and the harmless treatment rate of domestic garbage), using the standardized entropy method. In this way, a comprehensive ERS score was obtained for each region in China, which comprehensively and accurately reflects the ERS level of each region. To prevent the deviation caused by intra-provincial differences, the panel data of the 283 Chinese cities at prefecture level and above were selected, and empirical analysis was conducted in eastern, central, and western regions, making the research more pertinent.

\section{THEORETICAL ANALYSIS}

From the micro level, this paper uses the Cournot model to analyze the decision-making of enterprises. For an enterprise, the basic goal is to maximize its profit. During the production, the enterprise often produces environmental pollution, bringing negative externalities: the private cost will be smaller than social cost. In this case, the market mechanism will fail, and the resources will not be allocated effectively. To maximize social welfare, the government needs to implement ERS to restrict the enterprise and solve their externalities. Under the ERS, the enterprise will see a rise in the unit production cost. Here, the production decision-making of foreign-funded enterprises is analyzed by the cost-benefit method.

Suppose a country has a domestic enterprise and a foreignfunded enterprise; the two enterprises manufacture homogeneous product, and thus engage in a Cournot competition. The market demand of the product can be expressed as $\mathrm{p}=\mathrm{a}-\mathrm{q}$, where $\mathrm{p}$ is the market price of the product, $\mathrm{q}$ is the product quality, and $\mathrm{a}$ is a market size. Let $\mathrm{c}$ be the unit production cost of the enterprises. In the absence of ERS, the profits of the domestic and foreign-funded enterprises can be respectively calculated by:

$$
\begin{aligned}
& W^{d}=p q^{d}-c^{d} q^{d} \\
& W^{f}=p q^{f}-c^{f} q^{f}
\end{aligned}
$$

where, $\mathrm{W}$ is profit; superscript $\mathrm{d}$ is the domestic enterprise; superscript $\mathrm{f}$ is the foreign-funded enterprise.

Let $\beta$ and $\theta$ be the increments of the unit production cost and unit production profit, respectively, after the government implements ERS. Then, the profits of the domestic and foreign-funded enterprises under ERS can be respectively calculated by:

$$
\begin{aligned}
& W^{d}=p q^{d}-c^{d} q^{d}-\beta q^{d}+\theta q^{d} \\
& W^{f}=p q^{f}-c^{f} q^{f}-\beta q^{f}+\theta q^{f}
\end{aligned}
$$

During the Cournot competition, each enterprise adjusts its output for the maximal profit. The optimal outputs of the domestic and foreign-funded enterprises can be obtained by taking the first-order derivative of profit relative to output:

$$
\begin{aligned}
& \frac{d w^{d}}{d q^{d}}=a-2 q^{d}-q^{f}-c^{d}-\beta+\theta=0 \\
& \frac{d w^{f}}{d q^{f}}=a-2 q^{f}-q^{d}-c^{f}-\beta+\theta=0
\end{aligned}
$$

From the above formulas, the optimal equilibrium strategies, i.e. the optimal outputs, of the domestic and foreign-funded enterprises can be respectively obtained as:

$$
\begin{aligned}
& q^{d}=\frac{1}{3}\left(a-2 c^{d}-c^{f}-\beta+\theta\right) \\
& q^{f}=\frac{1}{3}\left(a-2 c^{f}-c^{d}-\beta+\theta\right)
\end{aligned}
$$

It is assumed that the output of an enterprise represents how much the enterprise invests in the place. Then, the higher the output, the greater the investment, and the more attractive the place is to foreign investment. As shown in formulas (7) and (8), the influence of government ERS on enterprises depends on the magnitude of $\beta$ and $\theta$, i.e. the increment of production cost induced by the ERS and the increment of profit brought by technological innovation. 
If the cost increment is greater than the profit increment, ERS has a negative impact on FDI inflow, that is, stricter ERS suppresses the inflow of FDI; if the cost increment is smaller than the profit increment, ERS has a positive impact on FDI inflow, that is, stricter ERS promotes the inflow of FDI.

To be specific, the influence of FDI inflow is two-fold. On the one hand, after the implementation of ERS, the enterprise needs to purchase greener equipment, which pushes up cost and reduces profit margin; the output will decline as a part of operation funds is occupied, exerting a great impact on profit. On the other hand, stricter ERS forces the enterprise to transform and pursue technological innovation. The ensuing first-mover advantage will offset and even surpass the cost increment induced by ERS, making the enterprise more competitive on the international stage. Therefore, a reasonable ERS level will stimulate the enterprise to pursue technological innovation, which in turn brings benefits to the enterprise and the entire society. To prevent capital outflow, the government should implement ERS on a reasonable level.

\section{EMPIRICAL ANALYSIS}

\subsection{Model construction}

Referring the relevant literature and above theoretical results, an econometric model was designed as follows:

$$
F D I_{i t}=\beta_{0}+\beta_{1} E R S_{i t}+\beta_{2}\left(E R S_{i t}\right)^{2}+\phi \text { Contr }_{i t}+\varepsilon_{i t}
$$

where, FDI is the inflow of foreign capital; ERS is the regional ERS level; Contr is the other control variables; $\varepsilon$ is a random disturbance. Here, the FDI is characterized by the actually utilized FDI in each region; the quadratic term of ERS is introduced as an explanatory variable, because of the two-fold influence of stricter ERS: increasing production cost and lowering enterprise profit; promoting technological innovation, making the enterprise more competitive.

\subsubsection{Measurement of core explanatory variables}

The measuring results of ERS level vary with the selected indices. In most studies, only a single index is selected to measure ERS, such as pollution control expenditure, and the discharge fee (tax) for a certain pollutant. The single index cannot comprehensively measure the intensity of ERS in different regions of China.

To effectively measure the intensity of environmental protection in different regions of China, five indices were selected in view of the research purpose and data availability, including the removal rate of industrial sulfur dioxide, the removal rate of industrial fume, the comprehensive utilization rate of industrial solid waste, the treatment rate of domestic sewage, and the harmless treatment rate of domestic garbage. On this basis, the standardized entropy method was adopted to measure the ERS levels of the 283 Chinese cities at prefecture level and above, and derive the comprehensive ERS score of each region.

As a thermodynamic concept, entropy mainly describes the order of the entire system. Nowadays, the entropy method is widely used in the academia. In information theory, entropy is a measure of uncertainty. The greater the degree of dispersion of each index, the smaller the information entropy; a high information entropy means the index offers rich information, and has a great impact on the compressive evaluation; thus, such an index should be assigned a high weight. The inverse is also true.

Being an objective weighting method, the entropy method overcomes the stochasticity and subjectivity of subjective weighting method in the assignment of index weights, making the data more real and effective. As a result, this paper determines the weight of each index by information entropy, which reflects the degree of dispersion of sample data, and then evaluates the ERS levels of the 283 cities at prefecture level and above. The entropy method was implemented in the following steps:

Step 1. Process the original data into normalized, nonnegative data. Through mathematical transforms of relevant indices, eliminate the dimensional relationship between variables, making the data comparable. Besides, translate the data to ensure the meaningfulness of entropy calculation:

$$
\begin{gathered}
X_{i j}^{\prime}=\frac{X_{i j}-\min \left(X_{1 j}, X_{2 j}, \ldots, X_{n j}\right)}{\max \left(X_{1 j}, X_{2 j}, \ldots, X_{n j}\right)-\min \left(X_{1 j}, X_{2 j}, \ldots, X_{n j}\right)}+1(\mathrm{i}=1, \\
2, \ldots, \mathrm{n} ; \mathrm{j}=1,2, \ldots, \mathrm{m})
\end{gathered}
$$

where, $\mathrm{n}$ is the number of samples (cities); $\mathrm{m}$ is the number of indices; $X_{i j}$ is the original value of index $j ; \min \left(X_{1 j}, X_{2 j}, \ldots X_{\mathrm{n} j}\right)$ and $\max \left(X_{1 j}, X_{2 j}, \ldots X_{\mathrm{n} j}\right)$ are the minimum and maximum of index $j$ in all regions, respectively; $X_{i j}^{\prime}$ is the value of index $j$ after normalization and translation.

Step 2. Calculate the proportion $P_{i j}$ of city $i$ in index $j$ :

$$
P_{i j}=\frac{x_{i j}^{\prime}}{\sum_{i=1}^{n} X_{i j}^{\prime}}(\mathrm{i}=1,2, \ldots, \mathrm{n} ; \mathrm{j}=1,2, \ldots, \mathrm{m})
$$

where, $n$ is the number of samples; $m$ is the number of indices.

Step 3. Calculate the entropy of index $j$ :

$$
e_{j}=-k * \sum_{i=1}^{n} P_{i j} \ln \left(P_{i j}\right)(\mathrm{i}=1,2, \ldots, \mathrm{n} ; \mathrm{j}=1,2, \ldots, \mathrm{m})
$$

where, $k>0$ is a constant; $\ln$ is the natural logarithm; $e_{j} \geq 0$. The constant $k$ is related to the number of samples $n$. In general, $\mathrm{k}=1 / \ln n$, and then $0 \leq \mathrm{e} \leq 1$.

Step 4. Calculate the diversity coefficient of index $j$. For index $j$, the higher the diversity of $X_{i j}$, the greater its impact on the evaluation, and the smaller its entropy:

$$
\mathrm{g}_{j}=1-e_{j}
$$

where, $g_{j}$ is positively correlated with the importance of index $j$.

Step 5. Calculate the weight of index $j$ :

$$
W_{j}=\frac{g_{j}}{\sum_{j=1}^{m} g_{j}}(\mathrm{j}=1,2, \ldots, \mathrm{m})
$$

Step 6. Calculate the comprehensive ERS score:

$$
E R_{i}=\sum_{j=1}^{m} W_{j} * P_{i j}(\mathrm{i}=1,2, \ldots, \mathrm{n} ; \mathrm{j}=1,2, \ldots, \mathrm{m})
$$

Through the above method, the ERS intensities of the 283 cities at prefecture level and above in 2003-2016 were computed, producing the ERS scores of each region. Table 1 reports the ERS scores of some cities in 2010-2016. 
It can be seen that, the ERS scores of all cities were on the rise in recent years, indicating that the ERS level has been improving across China, the government has attached greater importance to environmental protection, and the public has a growing environmental awareness. Comparing the scores of cities in the eastern, central, and western regions, eastern cities, especially coastal cities like Tianjin, Shanghai, Qingdao, and Guangzhou, had higher ERS scores than the cities in the central and western regions. The results show that the overall ERS level of eastern cities is higher than that of central and western cities.

Table 1. The ERS scores of some cities in 2010-2016

\begin{tabular}{|c|c|}
\hline Cities & 2010201120122013201420152016 \\
\hline Beijing & $\begin{array}{lllllll}0.78 & 0.66 & 0.78 & 0.79 & 0.79 & 0.80 & 0.85\end{array}$ \\
\hline Tianjin & $\begin{array}{lllllll}0.84 & 0.77 & 0.85 & 0.87 & 0.87 & 0.88 & 0.95\end{array}$ \\
\hline Shijiazhuang & $\begin{array}{lllllll}0.84 & 0.75 & 0.78 & 0.77 & 0.84 & 0.89 & 0.92\end{array}$ \\
\hline Taiyuan & $\begin{array}{lllllll}0.75 & 0.67 & 0.76 & 0.76 & 0.71 & 0.80 & 0.81\end{array}$ \\
\hline Hohhot & $\begin{array}{lllllll}0.88 & 0.68 & 0.69 & 0.68 & 0.65 & 0.71 & 0.75\end{array}$ \\
\hline Shenyang & $\begin{array}{lllllll}0.73 & 0.70 & 0.79 & 0.76 & 0.72 & 0.83 & 0.86\end{array}$ \\
\hline Dalian & $\begin{array}{lllllll}0.80 & 0.66 & 0.78 & 0.82 & 0.73 & 0.81 & 0.90\end{array}$ \\
\hline Changchun & $\begin{array}{lllllll}0.65 & 0.67 & 0.75 & 0.79 & 0.79 & 0.82 & 0.90\end{array}$ \\
\hline Harbin & $\begin{array}{lllllll}0.54 & 0.58 & 0.75 & 0.76 & 0.73 & 0.79 & 0.87\end{array}$ \\
\hline Shanghai & $\begin{array}{lllllll}0.71 & 0.75 & 0.79 & 0.84 & 0.83 & 0.90 & 0.93\end{array}$ \\
\hline Nanjing & $\begin{array}{lllllll}0.73 & 0.63 & 0.83 & 0.79 & 0.79 & 0.76 & 0.82\end{array}$ \\
\hline Hangzhou & $\begin{array}{lllllll}0.76 & 0.68 & 0.78 & 0.81 & 0.73 & 0.79 & 0.84\end{array}$ \\
\hline Hefei & $\begin{array}{llllllll}0.71 & 0.70 & 0.79 & 0.84 & 0.79 & 0.83 & 0.86\end{array}$ \\
\hline Fuzhou & $\begin{array}{lllllll}0.74 & 0.79 & 0.82 & 0.83 & 0.85 & 0.84 & 0.88\end{array}$ \\
\hline Xiamen & $\begin{array}{lllllll}0.69 & 0.77 & 0.84 & 0.85 & 0.83 & 0.85 & 0.87\end{array}$ \\
\hline Nanchang & $\begin{array}{lllllll}0.79 & 0.70 & 0.80 & 0.81 & 0.77 & 0.86 & 0.92\end{array}$ \\
\hline Jinan & $\begin{array}{lllllll}0.76 & 0.59 & 0.84 & 0.86 & 0.85 & 0.88 & 0.95\end{array}$ \\
\hline Qingdao & $\begin{array}{lllllll}0.81 & 0.82 & 0.84 & 0.88 & 0.87 & 0.89 & 0.96\end{array}$ \\
\hline Zhengzhou & $\begin{array}{lllllll}0.65 & 0.61 & 0.79 & 0.80 & 0.77 & 0.81 & 0.90\end{array}$ \\
\hline Wuhan & $\begin{array}{lllllll}0.76 & 0.77 & 0.83 & 0.83 & 0.83 & 0.87 & 0.95\end{array}$ \\
\hline Changsha & $\begin{array}{lllllll}0.72 & 0.79 & 0.84 & 0.82 & 0.75 & 0.84 & 0.94\end{array}$ \\
\hline Guangzhou & $\begin{array}{lllllll}0.76 & 0.84 & 0.86 & 0.86 & 0.90 & 0.92 & 0.95\end{array}$ \\
\hline Shenzhen & $\begin{array}{lllllll}0.74 & 0.90 & 0.84 & 0.85 & 0.88 & 0.95 & 0.69\end{array}$ \\
\hline Nanning & $\begin{array}{lllllll}0.56 & 0.68 & 0.80 & 0.80 & 0.79 & 0.83 & 0.89\end{array}$ \\
\hline Haikou & $\begin{array}{lllllll}0.87 & 0.85 & 0.91 & 0.90 & 0.88 & 0.95 & 0.91\end{array}$ \\
\hline Chongqing & $\begin{array}{lllllll}0.75 & 0.73 & 0.79 & 0.81 & 0.78 & 0.81 & 0.86\end{array}$ \\
\hline Chengdu & $\begin{array}{lllllll}0.75 & 0.75 & 0.82 & 0.83 & 0.81 & 0.85 & 0.89\end{array}$ \\
\hline Guiyang & $\begin{array}{llllllll}0.80 & 0.74 & 0.74 & 0.75 & 0.65 & 0.60 & 0.72\end{array}$ \\
\hline Kunming & $\begin{array}{lllllll}0.81 & 0.43 & 0.78 & 0.76 & 0.69 & 0.73 & 0.68\end{array}$ \\
\hline Xi'an & $\begin{array}{lllllll}0.68 & 0.50 & 0.86 & 0.83 & 0.78 & 0.85 & 0.91\end{array}$ \\
\hline Lanzhou & $\begin{array}{lllllll}0.65 & 0.66 & 0.79 & 0.80 & 0.73 & 0.68 & 0.78\end{array}$ \\
\hline Xining & $\begin{array}{lllllll}0.50 & 0.57 & 0.66 & 0.66 & 0.71 & 0.74 & 0.79\end{array}$ \\
\hline Yinchuan & $\begin{array}{lllllll}0.77 & 0.78 & 0.70 & 0.70 & 0.86 & 0.91 & 0.95\end{array}$ \\
\hline Urumqi & $\begin{array}{llllllll}0.60 & 0.45 & 0.75 & 0.80 & 0.81 & 0.85 & 0.87\end{array}$ \\
\hline
\end{tabular}

Data sources: China City Statistical Yearbooks and China Statistical Yearbooks on Environment 2011-2017 (China Statistics Press).

\subsubsection{Other control variables}

Referring the relevant literature and above theoretical results, the following control variables were selected in the light of data availability:

(1) Gross regional product (GRP)

The GRP represents the level of economic development in a region. According to traditional theory on foreign investment, the larger the regional economy, the more attractive the region is to FDI. Therefore, the sign of GRP was expected to be positive.

\section{(2) Wage}

Production cost is the main consideration of the enterprise in location selection. Wage means labor cost. The lower the wage, the lower the labor cost. To acquire the comparative advantage of low labor cost, FDI tends to flow to the region with a low wage. This is in line with the early theory on the location selection of foreign investment. Hence, the sign of wage was expected to be negative. Here, the wage of a region is characterized by the mean wage of employees in that region.

(3) Human capital (Human)

Human capital is synonymous to productivity. Foreignfunded enterprises have relatively advanced production technology and management skills. Regions with a high human capital can provide foreign-funded enterprises with the necessary talents, and attract FDI more easily than other regions. Thus, the sign of human capital was expected to be positive. Here, the human capital of a region is characterized by the number of college students as a proportion of the total population of that region.

(4) Infrastructure (Infras)

According to the early theory on the location selection of foreign investment, sound infrastructure is critical to foreignfunded enterprises, because it reduces their operating cost and improves their profit. Good transport infrastructure is conducive to attracting and retaining FDI. Therefore, the sign of infrastructure was expected to be positive. Here, the infrastructure of a region is characterized by the road area of the cities in that region.

(5) Market size (Market)

According to the early theory on the location selection of foreign investment, foreign capital will not flow into a place unless the local market reaches a certain scale. A large market size benefits the FDI in a region. Thus, the sign of market size was expected to be positive. Here, the market size of a region is characterized by the population per unit area in that region.

The nonlinear relationship between the variables might lead to the problem of heteroscedasticity. To prevent the problem, this paper adopts the natural logarithm of each variable to design our econometric model:

$$
\begin{aligned}
\operatorname{LnFDI}_{i t}=\beta_{0}+ & \beta_{1} \text { LnERS }_{i t}+\beta_{2}\left(\text { LnERS }_{i t}\right)^{2}+\beta_{3} \text { LnGRP }_{i t} \\
& +\beta_{4} \text { LnWage }_{i t}+\beta_{5} \text { LnHuman }_{i t} \\
& +\beta_{6} \text { LnInfras }_{i t}+\beta_{7} \text { LnMarket }_{i t}+\varepsilon_{i t}
\end{aligned}
$$

\subsection{Data sources and descriptive analysis}

This paper mainly analyzes the panel data on 283 Chinese cities at prefecture level and above in 2003-2016, and empirically investigates the FDIs in eastern, central, and western regions based on economic gap.

The explained variable, the FDI of each city, was collected from China City Statistical Yearbooks and China Statistical Yearbooks. The actually utilized foreign capitals in some provinces were obtained from the official websites of local statistical bureaus and the Foreign Investment Department of the Ministry of Commerce. The original data, which are in units of USD 10,000, were converted into RMB based on the mean exchange rate of the current year. The mean exchange rates were acquired from the National Bureau of Statistics.

The core explanatory variables are about ERS. As mentioned before, a total of five indices (i.e. the removal rate of industrial sulfur dioxide, the removal rate of industrial fume, the comprehensive utilization rate of industrial solid waste, the treatment rate of domestic sewage, and the harmless treatment rate of domestic garbage) were selected, and combined with the standardized entropy method to compute the ERS levels of 283 cities at prefecture level and above, and derive the comprehensive ERS score of each region. 
The original data on the removal rate of industrial sulfur dioxide, and the removal rate of industrial fume were mainly obtained from China Statistical Yearbooks on Environment, and China City Statistical Yearbooks, and partly acquired from the Environmental Statistics Bulletins. The data on the other explanatory variables come from China City Statistical Yearbooks, China Labor Statistical Yearbooks, and the statistical bulletins of the relevant provinces.

The few missing data were completed through linear interpolation and mean growth rate estimation. The descriptive statistics of all variables are listed in Table 2 .

\section{RESULTS ANALYSIS}

\subsection{Analysis of benchmark regression results}

The empirical testing was conducted on Stata software. The F-test for panel data shows fixed-effects model is better than mixed regression. Through the Hausman test, the p-value was obtained as 0.0000 , indicating that fixed-effects model is better than random-effects model. Therefore, the fixed-effects model was adopted for regression.

Considering the obvious economic gap between eastern region and the other two regions, this paper estimates the ERS of each region on FDI inflow separately. Table 3 records the regression results.

(1) The first column in Table 3 presents the regression results of nationwide samples. It can be seen that ERS was significantly negative at the $1 \%$ level, reflecting the important impact of ERS on the location selection of foreign investment. It can also be seen that, the higher the ERS, the less the FDI inflow.

From the nationwide perspective, the influence of ERS is consistent with the pollution haven hypothesis. The reason is that ERS affects the decision-making of the enterprise via its impact on production cost. Facing strict ERS, the enterprise needs to purchase greener equipment to reduce pollution, which elevates the production cost. To a certain extent, this explains why some local governments compete to relax ERS, i.e. race to the bottom, to allure foreign investors.

As for the quadratic term of ERS, the sign was positive but the significance was not high. This means ERS has a U-shaped influence on FDI inflow. On the one hand, stricter ERS leads to higher cost and lower profit of the enterprise, thus suppressing FDI inflow; on the other hand, stricter ERS promotes the enterprise to pursue technological innovation, which boosts FDI inflow. Thus, there is an inflection point on the influence of ERS over FDI. Before that point, FDI increases with the decline of ERS; after that, FDI increases with ERS. This further testifies the results of theoretical analysis: the influence of ERS on FDI is two-fold.

(2) The second column in Table 3 reports the regression results on the samples in the eastern region. It can be seen that, in the eastern region, ERS has a positive impact on FDI inflow, and the impact passed the significance test at the 5\% level. Hence, the influence of ERS in the eastern region satisfies the Porter hypothesis: the growing ERS expands the scale of FDI, instead of inhibiting FDI inflow. The result agrees well with the reality.

Table 2. The descriptive statistics of variables

\begin{tabular}{ccccccc}
\hline Variable & Unit & Obs & Mean & Std. Dev. & Min & Max \\
\hline FDI & RMB 10,000 yuan & 3,962 & 433029 & $1.085 \mathrm{e}+06$ & 16.54 & $2.050 \mathrm{e}+07$ \\
ERS & 1 & 3,962 & 0.651 & 0.157 & 0.169 & 0.978 \\
ERS & 1 & 3,962 & 0.449 & 0.197 & 0.0285 & 0.956 \\
GRP & RMB 10,000 yuan & 3,962 & $1.510 \mathrm{e}+07$ & $2.320 \mathrm{e}+07$ & 206586 & $2.820 \mathrm{e}+08$ \\
Wage & RMB 10,000 yuan & 3,962 & 3.267 & 4.664 & 0.000981 & 275.2 \\
Human & $\%$ & 3,962 & 1.543 & 2.121 & 0.00592 & 13.11 \\
Infras & $10,000 \mathrm{~m}^{2}$ & 3,962 & 1456 & 2049 & 14 & 21490 \\
Market & Persons $/ \mathrm{km}^{2}$ & 3,962 & 425.4 & 325.2 & 4.700 & 2662 \\
\hline
\end{tabular}

Table 3. The benchmark regression results on the influence of ERS on FDI

\begin{tabular}{ccccc}
\hline Variables & Nationwide & Eastern & Central & Western \\
\hline Lners & $-0.413 * * *$ & $0.557 * *$ & $-0.515^{* * *}$ & $-0.369^{* *}$ \\
& $(0.258)$ & $(0.320)$ & $(0.345)$ & $(0.544)$ \\
lners2 & $0.264 *$ & $0.116^{*}$ & $0.115^{*}$ & $0.0731^{*}$ \\
& $(0.180)$ & $(0.240)$ & $(0.242)$ & $(0.352)$ \\
Lngrp & $1.310^{* * *}$ & $0.949 * * *$ & $0.893 * * *$ & $1.481 * * *$ \\
& $(0.0390)$ & $(0.0507)$ & $(0.0540)$ & $(0.0742)$ \\
Lnwage & $-0.0109 *$ & $0.222^{* * *}$ & $0.693 * * *$ & 0.0906 \\
& $(0.0741)$ & $(0.0836)$ & $(0.127)$ & $(0.148)$ \\
Lnhuman & $0.138^{* * *}$ & $0.277 * * *$ & $0.198 * * *$ & 0.0205 \\
& $(0.0226)$ & $(0.0302)$ & $(0.0312)$ & $(0.0414)$ \\
lninfras & $0.147 * * *$ & $0.113 * *$ & 0.0403 & $0.383 * * *$ \\
& $(0.0388)$ & $(0.0496)$ & $(0.0532)$ & $(0.0726)$ \\
lnmarket & $0.312 * * *$ & $0.180^{* * *}$ & $0.277 * * *$ & $0.0281 *$ \\
& $(0.0262)$ & $(0.0497)$ & $(0.0362)$ & $(0.0428)$ \\
Constant & $-12.06 * * *$ & $-5.303 * * *$ & $-4.782 * * *$ & $-16.04 * * *$ \\
& $(0.479)$ & $(0.617)$ & $(0.714)$ & $(0.964)$ \\
Observations & 3,962 & 1,414 & 1,400 & 1,148 \\
R-squared & 0.633 & 0.667 & 0.546 & 0.549 \\
Number of year & 14 & 14 & 14 & 14
\end{tabular}

Note: The bracketed data are standard deviations; $* * *, * *$, and $*$ indicate that the corresponding variable passes the significance test at the $1 \%, 5 \%$, and $10 \%$ level, respectively. 
Multinational enterprises prefer to invest in regions with strong talent reserve, mature market, and sound infrastructure. By virtue of superior location, complete infrastructure, and good business environment, the eastern region has become the first choice for foreign investment in recent years.

Moreover, some eastern coastal cities have taken the initiative to adjust the strategy for developing an open economy, and started to shift from invitation of investment to the selection of high-quality investment. These efforts contribute greatly to environmental protection and industrial upgrading.

Furthermore, the eastern region boasts many industrial clusters that require a good production environment, especially the clusters of clean industries like microelectronics. Therefore, stricter ERS can promote the development of these industries, and improve the attraction of foreign investment.

The quadratic term of ERS was significantly positive, indicating that the influence of ERS on FDI exhibited like a Ushaped curve. Since the influence of ERS in the eastern region has already crossed the inflection point, stricter ERS will only boost the inflow of foreign capital in this region.

(3) The third and fourth columns in Table 3 display the regression results on the central and western samples, respectively.

For the central region, the regression results were similar to those on nationwide samples: the ERS was significantly negative at the $1 \%$ level, and its elasticity coefficient was greater than that on nationwide samples. Hence, the situation in the central region satisfies the pollution haven hypothesis, i.e. stricter ERS inhibits the inflow of FDI.

For the western region, ERS also had a negative impact on foreign capital inflow, but the impact was not highly significant. The situation in the western region also meets the pollution haven hypothesis. This also means cost is an important consideration of foreign investors before investing in central and western regions.

Admittedly, some foreign investments have migrated to the central and western regions, under the strategies of Western Development and Rise of Central China. However, the central and western regions lagged far behind the eastern region in terms of economy, infrastructure, business environment, and industrial supports. Therefore, foreign enterprises will weigh carefully about the cost before moving to these regions.

Relaxing ERS will enable enterprises to slash cost and increase profit. For central and western regions, the influence of ERS has not passed the inflection point, and the ERS level has a negative correlation with the inflow of FDI.

(4) The regression results on the other control variables were summarized as follows. Like the previous studies, our research finds that GNP, which reflects the level of economic development of a region, has a significant positive correlation with FDI inflow. Hence, foreign capital tends to flow into economically developed regions. This trend echoes with our expectation.

For the mean wage of employees, on nationwide samples, the wage, a mirror of labor cost, is negatively correlated with FDI inflow. This means FDI tends to flow to regions with a low wage, in pursuit of the comparative advantage of low labor cost. In the eastern and central regions, wage has a significantly positive correlation with FDI inflow, which goes against our expectation. A possible reason is that those earning a high wage have a high living standard and create a large market demand, which stimulates the inflow of foreign capital.

The human capital has a significantly positive correlation with FDI. High-end talents are particularly important to multinational enterprises. Regions with a high human capital can provide foreign-funded enterprises with lots of talents, and attract FDI more easily than other regions. This finding agrees well with our expectation.

The infrastructure also has a significantly positive correlation with FDI. Studies have shown that infrastructure is the second most important consideration of foreign-funded enterprises in location selection, which reflects the significance of infrastructure to the introduction of foreign capital. Note that the infrastructure presented a significant positive correlation on western samples, and had an elastic coefficient greater than that on eastern and central samples. Thus, the western region must strive to improve its infrastructure.

The market size, as expected previously, has a significantly positive correlation with FDI. This relationship is the same with the reality: the larger the market, the greater the demand for foreign investment, and the easier it is to attract and retain foreign investment.

\subsection{Instrumental variable estimation}

ERS has a special effect on the location selection of FDI. The inflow of FDI is affected by ERS, and, in return, exerts an impact on ERS. Most foreign capitals flow to manufacturing, a pollution-intensive industry. This trend has an influence on regional ERS level. In short, ERS and FDI mutually affect and interact with each other, indicating that ERS is an endogenous variable. Thus, nationwide and regional samples were subject to an endogeneity test (Hausman value $=0$ ). The test results confirm the existence of endogeneity.

To eliminate endogeneity, an instrumental variable was selected by two principles: the instrumental variable must be highly correlated with the endogenous explanatory variable to be replaced; the instrumental variable should not have any correlation with the random error and other explanatory variables. Drawing on the research of Shen Kunrong [33], this paper chooses the ventilation coefficient (LnVC) as the instrumental variable of ERS.

Theoretically, cities with a low ventilation coefficient often implement strict ERS. So, there is a correlation between ERS variables and ventilation coefficient [33]. Besides, the ventilation coefficient only depends on natural phenomena like regional climate. It can be said that the ventilation coefficient only affects FDI inflow, without any other action mechanism. Thus, it is suitable to select this coefficient as the instrumental variable of ERS.

The ventilation coefficient equals the wind speed multiplied by the height of the boundary layer. The relevant data were collected from the ERA-Interim database of the European Center for Medium-Range Weather Forecasts (ECMWF), which provides the grid data on wind speed at the height of $10 \mathrm{~m}$ and the height of boundary layer. In this paper, the ventilation data of each grid are calculated for each year, and matched with the sample cities by latitude and longitude. In this way, the ventilation coefficients of the 283 cities in 2003 2016 were obtained. Some of the obtained data are listed in Table 4. 
Table 4. The ventilation coefficients of some cities in 20102016

\begin{tabular}{|c|c|}
\hline Cities & 1020111201220152017201 \\
\hline & 7.758 .117 .677 .277 .69 \\
\hline & $7.628 .21 \quad 7.707 .217$ \\
\hline & 57.517. \\
\hline & 7.517 .027 .387 .247 \\
\hline & 6. \\
\hline She & $807.657 .36 \varepsilon$ \\
\hline & $\begin{array}{lllllll}8.58 & 8.68 & 8.40 & 8.23 & 8.45 & 8.37 & 8.56\end{array}$ \\
\hline Char & $\begin{array}{lllllll}7.33 & 6.91 & 7.23 & 7.06 & 7.64 & 7.42 & 7.54\end{array}$ \\
\hline & $\begin{array}{lllllll}7.76 & 6.99 & 7.28 & 7.06 & 7.58 & 7.23 & 7.72\end{array}$ \\
\hline Sha & $\begin{array}{lllllll}8.04 & 8.49 & 8.40 & 7.99 & 8.24 & 8.22 & 8.27\end{array}$ \\
\hline & 7.808 .148 .167 .567 \\
\hline Har & 7.407 .837 .737 .227 \\
\hline & $\begin{array}{lllllll}7.80 & 8.07 & 8.02 & 7.44 & 7.69 & 7.65 & 7.96\end{array}$ \\
\hline $\mathrm{F}$ & $\begin{array}{lllllll}7.02 & 7.12 & 6.83 & 7.05 & 7.39 & 7.19 & 7.06\end{array}$ \\
\hline & 7.527 .747 .417 .567 .877 \\
\hline Nan & $7.207 .997 .767 .287 .48 \quad 7$. \\
\hline & $\begin{array}{lllllll}7.98 & 8.04 & 7.88 & 7.24 & 7.93 & 7.90 & 7.90\end{array}$ \\
\hline Q & 8.408 .728 .317 .938 \\
\hline ou & 7.477 .687 .507 .057 .467 \\
\hline & 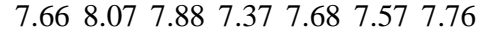 \\
\hline $\mathrm{a}$ & $\begin{array}{lllllll}7.62 & 8.10 & 7.90 & 7.30 & 7.68 & 7.57 & 7.75\end{array}$ \\
\hline ou & 7.277 .937 .487 .527$. \\
\hline She & $\begin{array}{lllllll}7.57 & 8.05 & 7.62 & 7.76 & 8.05 & 7.93 & 7.64\end{array}$ \\
\hline & 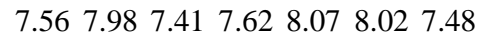 \\
\hline & $\begin{array}{lllllll}8.20 & 8.41 & 8.05 & 8.36 & 8.51 & 8.52 & 7.99\end{array}$ \\
\hline Cho & $\begin{array}{lllllll}6.91 & 7.58 & 7.48 & 6.81 & 6.58 & 6.72 & 7.26\end{array}$ \\
\hline & $6.64 \quad 7.20 \quad 7.02 \quad 6.84 \quad 6.66 \quad 6.616 .90$ \\
\hline & 7.197 .367 .107 .497 .637 .497 .29 \\
\hline & $\begin{array}{lllllll}7.61 & 8.25 & 8.41 & 7.98 & 7.50 & 7.19 & 8.02\end{array}$ \\
\hline & $7.087 .467 .27 \quad 6.897 .147$ \\
\hline Lanzhou & $\begin{array}{lllllll}6.64 & 6.36 & 6.44 & 5.98 & 6.46 & 6.75 & 6.63\end{array}$ \\
\hline & $6.74 \quad 6.30 \quad 5.61 \quad 5.31 \quad 5.38 \quad 5.98 \quad 6.64$ \\
\hline & $\begin{array}{lllllll}6.63 & 6.23 & 5.75 & 5.84 & 6.02 & 6.24 & 6.53\end{array}$ \\
\hline & $\begin{array}{lllllll}5.03 & 4.93 & 4.62 & 4.66 & 4.60 & 4.99 & 4.45\end{array}$ \\
\hline
\end{tabular}

Table 5. The estimation results of instrumental variable on nationwide and regional samples

\begin{tabular}{ccccc}
\hline Variables & Nationwide & Eastern & Central & Western \\
\hline lners & $-0.766^{* * *}$ & $0.640^{* *}$ & $-0.544^{* * *}$ & $-0.479^{*}$ \\
& $(0.243)$ & $(0.191)$ & $(0.321)$ & $(0.290)$ \\
lngrp & $0.780^{* * *}$ & $1.013 * * *$ & $1.081 * * *$ & $0.932^{* * *}$ \\
& $(0.261)$ & $(0.0825)$ & $(0.123)$ & $(0.178)$ \\
lnwage & $-0.439 * *$ & $0.113^{*}$ & $0.266^{*}$ & 0.0310 \\
& $(0.0913)$ & $(0.021)$ & $(0.128)$ & $(0.0364)$ \\
lnhuman & $0.181 *$ & $0.330^{* * *}$ & $0.208 * * *$ & $0.119 *$ \\
& $(0.0226)$ & $(0.0304)$ & $(0.0294)$ & $(0.0675)$ \\
lninfras & $0.144 * * *$ & $0.164 * *$ & 0.0366 & $0.932 * * *$ \\
& $(0.0387)$ & $(0.0541)$ & $(0.0552)$ & $(0.178)$ \\
lnmarket & $0.485 *$ & $0.262^{* * *}$ & $0.302 * * *$ & 0.138 \\
& $(0.056)$ & $(0.0543)$ & $(0.0367)$ & $(0.443)$ \\
Constant & $-7.582^{* * *}$ & $-4.159 * * *$ & $-5.483 *$ & $-11.84 * * *$ \\
& $(2.658)$ & $(1.521)$ & $(3.230)$ & $(4.425)$ \\
\hline
\end{tabular}

Note: The bracketed data are standard deviations; ***,**, and * indicate that the corresponding variable passes the significance test at the $1 \%, 5 \%$, and $10 \%$ level, respectively.

Two-stage least squares (LS) method was adopted to estimate the instrumental variable. The estimation results are shown in Table 5. It can be seen that the estimated results are basically consistent with the benchmark regression results. On nationwide samples, stricter ERS clearly inhibited FDI inflow, and the elasticity coefficient was greater than that of benchmark regression. On eastern samples, stricter ERS promoted FDI inflow, and the elasticity coefficient was slightly higher than that of benchmark regression. On central and western samples, ERS significantly inhibited FDI inflow, the same as that on nationwide samples. Therefore, the results of benchmark regression are further validated.

\subsection{Robustness test}

To further verify the influence of ERS on FDI inflow, a robustness test was carried out to check the robustness and reliability of the results. The removal rate of industrial sulfur dioxide, which is widely used as a single index to measure ERS intensity, was chosen to characterize the ERS level. Normally, the greater the removal rate of industrial sulfur dioxide, the stricter the ERS. The relevant data were obtained from China City Statistical Yearbooks and China Statistical Yearbooks on Environment. The results of robustness test are recorded in Table 6.

The test results show that, on nationwide, central, and western samples, stricter ERS hinders the inflow of foreign capital; on eastern samples, stricter ERS promotes FDI inflow. However, the significance levels were not as high as those of benchmark regression. The test results verify the correctness of the benchmark regression results, and highlight the necessity of measuring ERS level with a comprehensive index.

Table 6. The results of robustness test

\begin{tabular}{ccccc}
\hline Variables & Nationwide & Eastern & Central & Western \\
\hline lnso2 & $-0.514^{* *}$ & $0.876^{*}$ & $-0.433^{*}$ & $-0.362^{*}$ \\
& $(0.169)$ & $(0.532)$ & $(0.321)$ & $(0.175)$ \\
lngrp & $1.131^{*}$ & $1.314 *$ & 0.910 & 0.672 \\
& $(0.452)$ & $(0.556)$ & $(0.646)$ & $(0.477)$ \\
lnwage & 0.033 & $-0.231 * * *$ & -0.024 & $0.544 *$ \\
& $(0.143)$ & $(0.045)$ & $(0.280)$ & $(0.321)$ \\
lnhuman & $0.44 * *$ & 0.538 & $0.330 * * *$ & $0.519 * *$ \\
& $(0.194)$ & $(0.831)$ & $(0.0304)$ & $(0.218)$ \\
lninfras & 0.148 & $0.171 * *$ & $0.132 * *$ & $0.701 * * *$ \\
& $(0.107)$ & $(0.062)$ & $(0.0581)$ & $(0.099)$ \\
lnmarket & $0.613 *$ & $0.304 * *$ & $0.262 * * *$ & 0.185 \\
& $(0.097)$ & $(0.098)$ & $(0.0543)$ & $(0.246)$ \\
Constant & $-6.97 * * *$ & $-7.901 * * *$ & -2.051 & 0.148 \\
& $(2.18)$ & $(3.018)$ & $(2.370)$ & $(0.107)$ \\
\hline
\end{tabular}

Note: The bracketed data are standard deviations; $* * *, * *$, and * indicate that the corresponding variable passes the significance test at the $1 \%, 5 \%$, and $10 \%$ level, respectively.

\section{CONCLUSIONS}

This paper adopts entropy method to measure the ERS intensities of 283 Chinese cities at prefecture level and above in 2003-2016, and employs the fixed-effects model to empirically analyze the influence of the ERS levels in these cities on the location selection of FDI in China.

Whereas the existing studies only evaluate ERS intensity with a single index, this paper measures ERS intensity based on five indices, namely, the removal rate of industrial sulfur dioxide, the removal rate of industrial fume, and the comprehensive utilization rate of industrial solid waste, with the aid of standardized entropy method. Our approach can accurately demonstrate the ERS level of each city.

Besides, the influence of ERS on foreign capital inflow in eastern, central, and western regions was discussed separately, 
from the angle of economic gap. Considering the endogeneity of ERS, the ventilation coefficient was chosen as the instrumental variable, and the two-stage LS method was introduced to eliminate the endogeneity. The robustness of the measurement was also tested.

Through statistical analysis and empirical tests, the following conclusions were put forward: The regression results on nationwide, central, and western samples indicate that the influence of ERS variable was significantly negative. This means ERS is indeed an important consideration of foreign investors in location selection. Besides, stricter ERS hinders the inflow of FDI, which agrees with the pollution haven hypothesis. On eastern samples, stricter ERS promotes FDI inflow, that is, the situation in eastern region meets Porter hypothesis. By virtue of superior location, complete infrastructure, and good business environment, the eastern region has become the first choice for foreign investment.

Based on the above findings, the following suggestions were presented for ERS policymakers:

(1) The ERS level must be designed reasonably. To stimulate regional economy, some local governments compete to relax ERS to allure foreign investors. In other words, the foreign investment is attracted at the cost of environment. The local governments must realize that this strategy is not sustainable. For foreign-funded enterprises, good business environment, low labor cost, and huge market size are more attractive than relaxed ERS.

The local governments must also recognize that stricter ERS can force enterprises to pursue technological innovation, which will make them more competitive and earn extra profit to offset the cost increment indued by ERS. A moderate increase in ERS level will amplify the inflow of clean foreign investment.

For these reasons, local governments should design a reasonable ERS level, rather than building increase ERS intensity, to bolster technological innovation among enterprises, which in turn brings benefits to the enterprise and the entire society.

(2) The eastern region and the central and western regions should implement different ERS policies and utilize regionspecific ERS instruments. Depending on the actual situation in the region, the governments at all levels need to formulate differentiated investment policies and ERS intensities, and modify them in a timely manner to suit the local conditions.

(3) To promote industrial transformation and upgrading, the eastern region should accelerate the development of an innovative economy. In terms of investment invitation, special attention should be paid to the introduction of clean industries, the learning of advanced foreign technologies, and the cultivation of environmental awareness.

To realize the rise of Central China, the central region should learn from the eastern region, protect the local environment during investment invitation, and attract hightech industries to enhance the comprehensive strength of the region.

Due to its remoteness and poor infrastructure, the western region must invest more on infrastructure construction to reduce the cost of foreign investment. This region has a harsh natural environment and a weak environmental carrying capacity. If polluting industries are relocated here, the environmental balance will be easily undermined. To prevent this situation, the western region should be alert to potential risks and think forward in the utilization of foreign capital. The ERS level must be designed in line with local conditions, and the local pillar industries should be supported with favorable policies. To narrow the economic gap with eastern and central regions, the western region needs to construct convenient infrastructure, introduce novel technologies, and step up innovation.

It should be noted that this research has certain limitations in sample data and research method. For one thing, the authors did not collect all the actually utilized FDIs of all cities at prefecture level and above, due to the sheer volume of samples and the lack of statistics in some cities. The missing data in some years were completed through linear interpolation. This might result in certain deviation in the empirical results. For another, econometric method is a popular and scientific tool in new economic geography. However, this instrument was not adopted in our empirical analysis, owing to the missing data and strategy limitation. The econometric method will be further explored in the future research.

\section{ACKNOWLEDGMENT}

This paper was supported by The National Social Science Fund of China (Grant No.: 14BJL053) and Humanities and Social Sciences Planning Fund of the Ministry of Education (Grant No.: 19YJA790107)

\section{REFERENCES}

[1] Walter, I., Ugelow, J.L. (1979). Environmental policies in developing countries. Ambio, pp. 102-109. https://doi.org/10.5771/0506-7286-1981-1-95

[2] Wang, H., Liu, H. (2019). Foreign direct investment, environmental regulation, and environmental pollution: an empirical study based on threshold effects for different Chinese regions. Environmental Science and Pollution Research, 26(6): 5394-5409. https://doi.org/10.1007/s11356-018-3969-8

[3] Zhang, W., Li, G., Uddin, M.K., Guo, S. (2020). Environmental regulation, foreign investment behavior, and carbon emissions for 30 provinces in China. Journal of Cleaner Production, 248: 119208. https://doi.org/10.1016/j.jclepro.2019.119208

[4] Birdsall, N., Wheeler, D. (1993). Trade policy and industrial pollution in Latin America: Where are the pollution havens? The Journal of Environment \& Development, 2(1): https://doi.org/10.1177/107049659300200107

[5] List, J.A., Co, C.Y. (2000). The effects of environmental regulations on foreign direct investment. Journal of Environmental Economics and Management, 40(1): 1-20. https://doi.org/10.1006/jeem.1999.1095

[6] Drukker, D., Millimet, D.L. (2007). Assessing the pollution haven hypothesis in an interdependent world. Southern Methodist University Department of Economics, Departmental Working Papers.

[7] Dam, L., Scholtens, B. (2012). The curse of the haven: The impact of multinational enterprise on environmental regulation. Ecological Economics, 78: 148-156. https://doi.org/10.1016/j.ecolecon.2012.04.011

[8] Dijkstra, B.R., Mathew, A.J., Mukherjee, A. (2011). Environmental regulation: An incentive for foreign direct investment. Review of International Economics, 19(3): 568-578. 
9396.2011.00966.x

[9] Elliott, R.J., Zhou, Y. (2013). Environmental regulation induced foreign direct investment. Environmental and Resource Economics, 55(1): 141-158. https://doi.org/10.1007/s10640-012-9620-0

[10] Kim, Y., Rhee, D.E. (2019). Do stringent environmental regulations attract foreign direct investment in developing countries? Evidence on the "Race to the Top" from cross-country panel data. Emerging Markets Finance and Trade, 55(12): 2796-2808. https://doi.org/10.1080/1540496X.2018.1531240

[11] Ullah, A., Zhao, X., Abdul Kamal, M., Zheng, J. (2020). Environmental regulations and inward FDI in China: Fresh evidence from the asymmetric autoregressive distributed lag approach. International Journal of Finance \& Economics. https://doi.org/10.1002/ijfe.2218

[12] Hanna, R. (2010). US environmental regulation and FDI: evidence from a panel of US-based multinational firms. American Economic Journal: Applied Economics, 2(3): 158-189. https://doi.org/10.1257/app.2.3.158

[13] Chung, S. (2014). Environmental regulation and foreign direct investment: Evidence from South Korea. Journal of Development Economics, 108: 222-236. https://doi.org/10.1016/j.jdeveco.2014.01.003

[14] Millimet, D.L., Roy, J. (2016). Empirical tests of the pollution haven hypothesis when environmental regulation is endogenous. Journal of Applied $\begin{array}{lll}\text { Econometrics, } & 31(4): & 652-677 .\end{array}$ https://doi.org/10.1002/jae.2451

[15] Lin, L., Sun, W. (2016). Location choice of FDI firms and environmental regulation reforms in China. Journal of Regulatory Economics, 50(2): 207-232. https://doi.org/10.1007/s11149-016-9303-9

[16] Naughton, H.T. (2014). To shut down or to shift: Multinationals and environmental regulation. Ecological Economics, 102: 113-117. https://doi.org/10.1016/j.ecolecon.2014.03.013

[17] Cai, X., Lu, Y., Wu, M., Yu, L. (2016). Does environmental regulation drive away inbound foreign direct investment? Evidence from a quasi-natural experiment in China. Journal of Development Economics, 123: 73-85. https://doi.org/10.1016/j.jdeveco.2016.08.003

[18] Xu, J., Zhou, M., Li, H. (2016). ARDL-based research on the nexus among FDI, environmental regulation, and energy consumption in Shanghai (China). Natural Hazards, 84(1): 551-564 https://doi.org/10.1007/s11069-016-2441-7

[19] Geonwoo, P. (2017). An empirical study of impact of Chinese environmental regulation on south Korea's foreign direct investment. The Korea Local Administration Review, 31: 221-252.

[20] Li, W.H., Li, C., Huang, W.C., Dong, C.J. (2017). Effect of environmental regulation on the manufacturing FDI in China: Spatial econometric studies. Bulg. Chem. Commun, 49: 26-31.

[21] Mulatu, A. (2017). The structure of UK outbound FDI and environmental regulation. Environmental and Resource Economics, 68(1): 65-96. https://doi.org/10.1007/s10640-017-0145-4

[22] Cheng, Z., Li, L., Liu, J. (2018). The spatial correlation and interaction between environmental regulation and foreign direct investment. Journal of Regulatory Economics, 54(2): 124-146. https://doi.org/10.1007/s11149-018-9366-X

[23] Yang, Y., Niu, G., Tang, D., Zhu, M. (2019). Does environmental regulation affect the introduction of foreign direct investment in China?--Empirical research based on the spatial Durbin model. Polish Journal of Environmental Studies, 28(1): 415-424. https://doi.org/10.15244/pjoes/83692

[24] Ge, Y., Hu, Y., Ren, S. (2020). Environmental regulation and foreign direct investment: Evidence from China's eleventh and twelfth five-year plans. Sustainability, 12(6): 2528. https://doi.org/10.3390/su12062528

[25] Dean, J. M., Lovely, M. E., Wang, H. (2005). Are foreign investors attracted to weak environmental regulations? Evaluating the evidence from China. The World Bank. https://doi.org/10.1596/1813-9450-3505

[26] Eskeland, G.S., Harrison, A.E. (2003). Moving to greener pastures? Multinationals and the pollution haven hypothesis. Journal of Development Economics, 70(1): 1-23. https://doi.org/10.1016/S0304-3878(02)00084-6

[27] Zugravu, N., Ben Kheder, S. (2008). The pollution haven hypothesis: A geographic economy model in a comparative study.

[28] Hwang, Y.S., Dong, X., Choi, W. (2016). Environmental regulation effects revisited: Channel effects on industrial economic performance. Productive Treatise (Old Productivity Research), 30(2): 50-74. https://doi.org/10.15843/kpapr.30.2.201606.27

[29] Shadbegian, R., Wolverton, A. (2010). Location decisions of US polluting plants: Theory, Empirical Evidence, and Consequences, 4(1): 1-49. https://doi.org/10.22004/ag.econ.280885

[30] Chakraborty, D., Mukherjee, S., (2013). How do trade and investment flows affect environmental sustainability? Evidence from panel data. Environmental Development, 6(1): 34-47. https://doi.org/10.1016/j.envdev.2013.02.005

[31] Adeel-Farooq, R.M., Abu Bakar, N.A., Olajide Raji, J. (2018). Green field investment and environmental performance: A case of selected nine developing countries of Asia. Environmental Progress \& Sustainable Energy, 37(3): 1085-1092. https://doi.org/10.1002/ep.12740

[32] List, J.A. (2001). US county-level determinants of inbound FDI: evidence from a two-step modified count data model. International Journal of Industrial Organization, 19(6): 953-973. https://doi.org/10.1016/S0167-7187(99)00051-X

[33] Shen, K.R., Jin, G., Fang, X. (2017). Does environmental regulation cause pollution to transfer nearby. Economic Research Journal, 52(5): 44-59. 